\title{
Culture in Health Care in the Republic of Serbia
}

\author{
Ivan Stevanović ${ }^{1}$, Milena Gajić-Stevanović ${ }^{2}$, Jovana Aleksić3 \\ 'University of Belgrade, Faculty of Political Sciences, Belgrade, Serbia; \\ 2Public Health Institute of Serbia "Dr Milan Jovanović Batut", Belgrade, Serbia; \\ ${ }^{3}$ Belgrade Chamber of Commerce, Belgrade, Serbia
}

\begin{abstract}
SUMMARY
Culture encompasses entire societies, influences everything we feel, see, do and believe and shape the way we approach the world around us. Culture is an inseparable part of human existence and as such an important part of health and health care. The aim of this paper was to present specific forms of culture in health care that have influence on the quality of health care system, as well as to investigate in which capacity is work on culture in the health care system in Serbia represented. National and international literature and documentation was processed using analytical methods - observation and comparative method. Health culture as responsibility of health care users and culture in health care as responsibility of health care employees are key factors in improving the health system in Serbia. The most important step has been made with the strategic plan of the Government of the Republic of Serbia in 2010, however, everyone has to accept and understand the importance of culture in health care and apply its rules into the practise.

Keywords: culture in health care; quality in health care; health care prevention and promotion
\end{abstract}

\section{INTRODUCTION}

Culture is, undoubtedly, one of very important, if not the most significant aspects of human society. According to the anthropologist André Malraux, it represents the key factor that sets human society apart from animals. Although each culture contains elements of many individuals, it is a social phenomenon expressed through the prism of social environment and interaction of members of society [1]. Culture influences our feelings, perceptions, work and beliefs, as well as the way we interact with the world around us. It is an inseparable part of human existence and as such an important factor in health and healthcare [2]. Two key concepts that link culture and health are: health culture and culture in health care.

\section{Health culture}

Health culture of health care users or even broader, health culture of a nation is closely associated with promotion and prevention in health care, with the aim to develop and promote health culture of the whole nation. It has been known that health culture of health care users can improve the quality of health services and contribute to better health of the population $[3,4]$. Proper nutrition, awareness of the potential health risks, regular maintenance of personal hygiene and medical screening are just some of the steps which contribute significantly to improving health status of medical service users and easier work of healthcare service providers [5].

\section{Culture in health care}

Unlike health culture, culture in health care is linked to the quality of health care and is one of primary methods for improving the quality of health care. While health culture is related to health care users, culture in health care includes organizational and processing structure, which leads to establishment of permanent improvement in health care, including culture of health care employees. Culture in health care is usually related to the culture of health care employees [6]. Achieving good communication with health care users is one of the most important tasks of health care employees and it has an effect on the satisfaction of health services' users. However, culture in health care is more than just communication between providers and users of health services. It includes respect and cooperation with colleagues as well as responsible, professional and ethical approach to work [6].

\section{OBJECTIVE}

The aim of this study was to, on the basis on existing documentation of planned activities for continuous improvement of the quality of health care in Serbia, present what has been done for enhancing culture in health care in Serbia and find answers to the following questions: 1) Is culture and in what form included in the plans for improving health care?; and 2) What can culture offer for healthcare and in which form? What can be affected? 


\section{CULTURE AND THE QUALITY OF HEALTH CARE}

Quality is included in health legislation of Serbia, with planned procedures for its implementation. The whole chapter of healthcare law deals with the quality of health care and the assessment of professional work and accreditation quality. Article 203 of the Health Law states that: "The quality of health care represents measures and actions which, in accordance with modern achievements of medical, dental and pharmaceutical science and practice, as well as modern achievements in science and practice, contribute to the higher level of quality of health services provided by health associates. Such practices increase the possibility of favourable outcomes and reduce the risk of adverse effects on the health and state of health of an individual and community as a whole" [7]. Article 213 defines the meaning of accreditation as: "Accreditation is the process of evaluating the quality of health care institutions based on implementation of optimal level of established practices' standards of health institutions in the particular field of health care or branch of medicine" [7].

Continuous improvement of the quality in health care is anticipated to be a permanent task of the Ministry of Health, Institute of Public Health of Serbia, Republican Health Insurance Fund, Institutes and the Public Health Institutes, including all health facilities [5]. Mutual task of all institutions is to improve the quality of health care, develop culture of quality and safety in health care and develop quality standards and indicators that could monitor quality and its improvement. Very important is increasing satisfaction of health care users as well as employees [6].

Continuous improvement of health care culture is planned within the framework related to [4]:

- monitoring of performance indicators at institutional levels and services in all health institutions through defined indicators and national accreditation program;

- monitoring of the quality committees work;

- monitoring the ongoing training of health workers as precondition for improving the quality of medical services;

- formulation of new guidelines for good clinical practice;

- development and implementation of clinical pathways;

- evaluation of user satisfaction with health service, as well as employees satisfaction;

- all types of education and training related to improving health care quality.

The following goals are expected after implementation of planned activities:

- establishment of a system of accountability for the quality of health care;

- consistent quality of health services;

- reducing variation in outcomes;

- improving standards of clinical practice;

- establishing a practice of reporting undesirable events;

- supporting good practice examples and emphasizing positive examples;
- more efficient use of health technologies;

- reduction of costs incurred due to the poor quality of work.

Unfortunately, there is nothing mentioned about the culture of communication, how health personnel should communicate with health care users or between them which is an important element of culture in health care.

\section{CULTURE IN THE HEALTH SYSTEM OF THE REPUBLIC OF SERBIA}

The results of a survey about the health of Serbian population in 2013, conducted by the Institute of Public Health of Serbia in 2014, showed that majority of population was satisfied with civil services (53.8\%) and with private health care services (64.6\%). This difference is probably a result of the attitude of employees in private practices towards users of health services. Improving the level of culture in health care has become a necessity to achieve satisfaction both of health care users and employees.

The Public Health Institute of Serbia has developed a Methodological Guide, which defines the procedures that medical institutions can utilize when reporting work quality indicators, such as waiting lists, continuing education of staff and satisfaction of patients [5]. Unfortunately, there is no instruction that first contact with a patient should begin with "Good afternoon" and a smile offered.

The strategy of the Government of the Republic of Serbia for continuous improvement of health care quality and patient safety for the period from 2010 to 2015 was provided with five strategic goals [7]:

1. Creating conditions for users-patients to be at the center of the health care system with the following: having surveys about user satisfaction with provided health services as well as data analysis; monitoring ombudsman's work at the level of healthcare institutions; highlighting notices for health service users as well as clearly displayed and marked boxes for users' comments;

2. Improving professional skills of health workers and raising awareness of the importance of continuous improvement of health care quality;

3. Creating conditions that promote continuous improvement of health care quality and patient safety in health care facilities by providing: records of undesirable events; adoption of plan for improving the quality of health care in each institution; monitoring and improvement of quality indicators and ranking institutions based on achieved results;

4. Providing safe, secure and cost-effective health technologies;

5. Providing financial incentives for continuous improvement of health care quality and patient safety.

This Strategy has not included patient's right to participate in the creation of the health policy. Also, it is not sufficient to have standards and norms on the paper they should be implemented in practice as well. There are some case reports from health care facilities where medical staff was carrying tubes with blood and other 
material for analysis completely unprotected which is unacceptable. In addition, none should be addressed as "Uncle, Grandmother, Grandfather ..."; these are just some of examples that need to be changed in order to achieve better quality of health care. Poor quality of health care can be easily identified in scandals of unexpected deaths or errors in therapy. In these cases, the person who has made error should be identified. Errors in health care exist but dealing with them in a proper manner is important for the health care system. However, it is very important to focus on the bigger picture of damage caused by poor health care. Work on continuous quality improvement is one of the mechanisms for development and improvement of the health care system [9].

\section{A COMPARISON OF THE QUALITY OF HEALTH CARE IN SERBIA WITH OTHER EUROPEAN COUNTRIES}

The quality of health care in the Republic of Serbia can best be assessed through comparison with other European countries, especially those in the same geographical region. The Euro Health Consumer Index (EHCI) is a project through which countries in Europe are compared and ranked based on pre-determined parameters. All collected parameters are divided into several groups. A special group is for parameters related to the outputs of prevention and promotion [10].

These are:

1. vaccination of infants with pentavalent vaccine (compares the percentage of infants vaccinated);

2. blood pressure level (compares the percentage of people over 25 years that have pressure higher than 140/90 mm Hg);

3. prevention of smoking (based on a complex scale that measures the price of cigarettes, smoking law regulations, tolerance of smoking in restaurants, public places, transportation, spending on antismoking campaigns, tobacco advertising and smoking, the prominence of the warning signs, treatments for quitting smoking, etc.);

4. prevention of alcohol (complex indicator, measuring consumption of alcoholic beverages by older than fifteen years);

5. physical activity (compares the quantity of physical exercise in compulsory education);

6. vaccination against human papilloma virus (assesses the existence of the National Program for Teenagers);

7. mortality in traffic (this is a new indicator, because the number of people killed in traffic is increasing rapidly in all countries).

Serbian outputs of promotion and prevention activities can be improved through increase in the percentage of vaccinated infants, prevention of smoking and alcohol consumption, and implementation of the National program for teenage girls. On the other hand, measures for reducing blood pressure are significantly more efficient than in other countries in the region (Table 1).

The behaviour of health personnel by health care users was not rated, but one chapter is focused on patients' rights and their awareness (Table 2).

Comparison between countries is done through basic indicators:

1. health law based on patients' rights;

2. patient organizations involved in health policy;

3. malpractice insurance;

4. patient's right to second opinion;

5. access to one's own medical records;

6. registry of conscientious physicians;

7. interactive $24 / 7$ telephone for medical assistance;

8. catalogue of service providers with ratings.

Former Yugoslav Republic of Macedonia achieved excellent results in most indicators. Serbia needs to im-

Table 1. Outputs of health prevention and promotion

Tabela 1. Izlazni efekti prevencije i promocije zdravlja

\begin{tabular}{|l|c|c|c|c|c|c|c|}
\hline $\begin{array}{l}\text { PREVENTION } \\
\text { PREVENCIJA }\end{array}$ & \multicolumn{7}{c|}{$\begin{array}{c}\text { Country } \\
\text { Država }\end{array}$} \\
\hline $\begin{array}{l}\text { Indicator } \\
\text { Indikator }\end{array}$ & $\begin{array}{l}\text { Serbia } \\
\text { Srbija }\end{array}$ & $\begin{array}{c}\text { Slovenia } \\
\text { Slovenija }\end{array}$ & $\begin{array}{c}\text { Croatia } \\
\text { Hrvatska }\end{array}$ & $\begin{array}{c}\text { Montenegro } \\
\text { Crna Gora }\end{array}$ & $\begin{array}{c}\text { Macedonia } \\
\text { Makedonija }\end{array}$ & $\begin{array}{c}\text { Albania } \\
\text { Albanija }\end{array}$ & $\begin{array}{c}\text { Bulgaria } \\
\text { Bugarska }\end{array}$ \\
\hline $\begin{array}{l}\text { Infant vaccination } \\
\text { Vakcinacija novorodenčadi }\end{array}$ & 2 & 3 & 3 & 2 & 3 & 3 & 2 \\
\hline $\begin{array}{l}\text { Blood pressure levels } \\
\text { Krvni pritisak }\end{array}$ & 2 & 1 & 1 & 1 & 1 & 1 & 1 \\
\hline $\begin{array}{l}\text { Smoking prevention } \\
\text { Prevencija pušenja }\end{array}$ & 1 & 1 & 1 & 1 & 1 & 1 & 1 \\
\hline $\begin{array}{l}\text { Alcohol prevention } \\
\text { Prevencija alkohola }\end{array}$ & 2 & 2 & 2 & 3 & 3 & 3 & 2 \\
\hline $\begin{array}{l}\text { Physical activity } \\
\text { Fizička aktivnost }\end{array}$ & 3 & 3 & 1 & 2 & 3 & 2 & 1 \\
\hline $\begin{array}{l}\text { HPV immunisation } \\
\text { HPV vakcinacija }\end{array}$ & 2 & 3 & 1 & 2 & 3 & 1 & 3 \\
\hline $\begin{array}{l}\text { Deaths in traffic } \\
\text { Smrtnost u saobraćaju }\end{array}$ & 13 & 15 & 10 & 13 & 16 & 12 & 12 \\
\hline $\begin{array}{l}\text { Total } \\
\text { Ukupno }\end{array}$ & 2 & 1 & 2 & 2 & 2 \\
\hline
\end{tabular}

Grading system: 1 = weak; 2 = good; 3 = excellent

Sistem ocenjivanja: 1 = slabo; $2=$ dobro; $3=$ odlično 
Table 2. Patients' rights and awareness

Tabela 2. Ocenjivanje prava pacijenata i njihove informisanosti

\begin{tabular}{|c|c|c|c|c|c|c|c|}
\hline \multirow{2}{*}{$\begin{array}{l}\text { PATIENT RIGHTS AND AWARENESS } \\
\text { PRAVA PACIJENATA I NJIHOVA INFORMISANOST } \\
\text { Indicator } \\
\text { Indikator }\end{array}$} & \multicolumn{7}{|c|}{$\begin{array}{l}\text { Country } \\
\text { Država }\end{array}$} \\
\hline & $\begin{array}{l}\text { Serbia } \\
\text { Srbija }\end{array}$ & $\begin{array}{l}\text { Slovenia } \\
\text { Slovenija }\end{array}$ & $\begin{array}{l}\text { Croatia } \\
\text { Hrvatska }\end{array}$ & $\begin{array}{c}\text { Montenegro } \\
\text { Crna Gora }\end{array}$ & $\begin{array}{l}\text { Macedonia } \\
\text { Makedonija }\end{array}$ & $\begin{array}{l}\text { Albania } \\
\text { Albanija }\end{array}$ & $\begin{array}{l}\text { Bulgaria } \\
\text { Bugarska }\end{array}$ \\
\hline $\begin{array}{l}\text { Health care law based on patient rights } \\
\text { Zdravstveni zakon zasnovan na pravima pacijenata }\end{array}$ & 3 & 3 & 3 & 2 & 3 & 3 & 1 \\
\hline $\begin{array}{l}\text { Patient organizations } \\
\text { Organizacije pacijenata }\end{array}$ & 2 & 2 & 2 & 1 & 3 & 3 & 3 \\
\hline $\begin{array}{l}\text { Malpractice insurance } \\
\text { Osiguranje od greške u lečenju }\end{array}$ & 2 & 2 & 1 & 2 & 2 & 1 & 1 \\
\hline $\begin{array}{l}\text { Right to a second opinion } \\
\text { Pravo na drugo mišljenje }\end{array}$ & 2 & 2 & 3 & 3 & 3 & 2 & 1 \\
\hline $\begin{array}{l}\text { Access to own medical records } \\
\text { Pristup svom zdravstvenom kartonu }\end{array}$ & 2 & 2 & 2 & 3 & 3 & 3 & 2 \\
\hline $\begin{array}{l}\text { Registry of conscientious physicians } \\
\text { Registar savesnih lekara }\end{array}$ & 1 & 2 & 2 & 1 & 3 & 3 & 3 \\
\hline $\begin{array}{l}24 \text { hour phone for medical assistance } \\
\text { 24-časovni telefon za zdravstvenu pomoć }\end{array}$ & 2 & 2 & 1 & 2 & 3 & 1 & 1 \\
\hline $\begin{array}{l}\text { Catalog of service providers with ratings } \\
\text { Katalog pružalaca usluga s ocenama }\end{array}$ & 1 & 1 & 1 & 1 & 2 & 1 & 1 \\
\hline $\begin{array}{l}\text { Total } \\
\text { Ukupno }\end{array}$ & 15 & 16 & 15 & 15 & 22 & 17 & 13 \\
\hline
\end{tabular}

Grading system: 1 = weak; $2=$ good; $3=$ excellent

Sistem ocenjivanja: 1 = slabo; 2 = dobro; $3=$ odlično

prove patient involvement in health policy by raising their awareness, as well as to establish a registry of careful physicians and directory of ranked healthcare providers (Table 2).

\section{CONCLUSION}

Health culture as responsibility of health care users and culture in health care as responsibility of health care employees are key factors in improving health system in Serbia. Analysis of existing documentation on the planned activities to continuously improve the quality of health care in Serbia showed that the most important step has been made with the strategic plan of the Government of the Republic of Serbia in 2010, however, there is still room for further progress. This primarily refers to involvement of the health care users in the development of health care policy and enforcement of already adopted standards and norms on a daily basis, to ensure that legislation does not work only "on paper". In addition, education of health care users cannot be overlooked in order to raise general awareness of the importance of health culture among those for whom the health system exists.

\section{REFERENCES}

1. Ilić M. Sociologija kulture i umjetnosti. 6th ed. Beograd: Narodna knjiga; 1980.

2. Kloskovska A. Sociologija kulture. Sarajevo: Biblioteka Transitus; 2003.

3. Elektronski časopis Euromed Infom. Available from: http://www. euromedinfo.eu/how-culture-\%20\%20\%20\%20\%20\%20influenceshealth-beliefs.html/.

4. Elektronski časopis The Health Culture. Available from: http://www. thehealthculture.com/.

5. Institut za javno zdravlje Srbije. Available from: http://www.batut.org. rs/index.php? category_id=64.

6. National Institute of Health. Available from: http://www.nih.gov/ clearcommunication/culturalcompetency.htm.

7. Ministarstvo zdravlja Republike Srbije. Available from: http://www. paragraf.rs/propisi/zakon_o_zdravstvenoj_zastiti.html.

8. Pencheon D, Guest C, Melzer D, Muir Gray JA. Oxford Handbook of Public Health Practice. 2nd ed. Oxford: University Press Inc; 2006.

9. Napier AD, Ancarno C, Butler B, Calabrese J, Chater A, Chatterjee H, et al. Culture and health. Lancet. 2014; 384:1607-39.

10. Gajić-Stevanović M, Aleksić J, Stojanović N, Živković S. Stanje zdravstvenog sistema Republike Srbije u periodu 2004-2012. godine. Stomatološki glasnik Srbije. 2014; 61(1):36-44. 


\title{
Kultura u zdravstvu u Republici Srbiji
}

\author{
Ivan Stevanović ${ }^{1}$, Milena Gajić-Stevanović2 , Jovana Aleksić3 \\ 'Univerzitet u Beogradu, Fakultet političkih nauka, Beograd, Srbija; \\ ${ }^{2}$ Institut za javno zdravlje Srbije „Dr Milan Jovanović Batut", Beograd, Srbija; \\ ${ }^{3}$ Privredna komora Beograda, Beograd, Srbija
}

\begin{abstract}
KRATAK SADRŽAJ
Uvod Kultura prožima celo društvo, utiče na sve što osećamo, vidimo, radimo i verujemo i oblikuje način na koji pristupamo svetu oko nas. Kultura je neodvojivi deo ljudskog postojanja i kao takav važan deo zdravlja i zdravstvene zaštite. Cilj ovog rada bio je da se predstave konkretni oblici kulture u zdravstvu koji utiču na kvalitet zdravstvenog sistema i istraži u kojoj je meri zastupljen rad na kulturi u sistemu zdravstvene zaštite u Srbiji. Domaća i strana literatura su analizirane pomoću analitičkih metoda posmatranja i komparativne metode. Zdravstvena kultura, kao odgovornost korisnika zdravstvene zaštite, i kultura u zdravstvu, kao odgovornost zaposlenih u zdravstvu, ključni su činioci u poboljšanju zdravstvenog sistema u Srbiji. Najvažniji korak je učinjen sa strateškim planom Vlade Republike Srbije 2010. godine, međutim, svako mora prihvatiti i razumeti važnost kulture u zdravstvu i primenjivati njena pravila u praksi.

Ključne reči: kultura u zdravstvu; kvalitet u zdravstvu; zdravstvena prevencija i promocija
\end{abstract}

\section{UVOD}

Kultura je nesumnjivo veoma važan, ako ne i najvažniji, činilac ljudskog društva. Prema mišljenju antropologa Anrija Malroa, ona je ključni faktor koji ljudsko društvo razlikuje i izdvaja od životinjskog. Iako svaka kultura sadrži i elemente individualne ličnosti, u globalu kultura je društveni fenomen i dolazi do izražaja tek ako se analizira kroz prizmu društvene sredine, tj. međusobne interakcije članova društva [1]. Kultura prožima čitava društva, utičući na sve što osećamo, vidimo, radimo i verujemo, ali i na način kojim pristupamo svetu oko sebe. Kultura je, dakle, neraskidiv deo ljudskog postojanja i samim tim važan činilac u sferi zdravstva i zdravstvene zaštite [2]. Dva ključna pojma koja povezuju kulturu i zdravstvo su „zdravstvena kultura“ $i$,kultura u zdravstvu“.

\section{Zdravstvena kultura}

Zdravstvena kultura korisnika zdravstvene zaštite, odnosno šire - zdravstvena kultura jednog naroda, blisko je povezana $s$ radom na promociji i prevenciji zdravstvene zaštite, s osnovnim ciljem razvijanja i unapređivanja zdravstvene kulture, kako korisnika zdravstvene zaštite, tako i naroda u celini. Puno se pisalo o tome kako zdravstvena kultura korisnika zdravstvene zaštite može da pomogne unapređenju kvaliteta usluga u zdravstvu i doprinese boljem zdravlju stanovništva [3,4]. Pravilna ishrana, svest o mogućim zdravstvenim rizicima, redovno održavanje lične higijene i provera zdravstvenog stanja samo su neki od koraka koji značajno doprinose poboljšanju zdravstvenog stanja korisnika medicinskih usluga i olakšavaju pružaocima ovih usluga obavljanje svog posla [5].

\section{Kultura u zdravstvu}

Za razliku od zdravstvene kulture, kultura u zdravstvu se vezuje za kvalitet zdravstvene zaštite i jedan je od primarnih metoda unapređenja kvaliteta zdravstvene zaštite. Dok zdravstvena kultura pripada domenu korisnika zdravstvene zaštite, kultura u zdravstvu obuhvata organizacionu i procesnu strukturu, koja vodi ka uspostavljanju stalnog unapređenja zdravstvene zaštite, uključujući i kulturu zaposlenih u zdravstvenim sistemima. Na kulturu zaposlenih u zdravstvenoj zaštiti se obično misli kada se među stanovništvom, odnosno među profesionalcima govori o kulturi u zdravstvu [6]. Ostvarivanje kvalitetne komunikacije s korisnicima zdravstvene zaštite jedan je od bitnijih faktora koji utiču na zadovoljstvo zdravstvenim uslugama i jedan od važnijih zadataka zaposlenih u zdravstvenom sektoru. Kultura u zdravstvu, međutim, predstavlja više od komunikacije između pružalaca i korisnika zdravstvenih usluga. Ona obuhvata poštovanje i dobru saradnju s kolegama, ali i odgovoran, profesionalan i etički pristup poslu [6].

\section{CILJ RADA}

Cilj ovog rada je bio da se na osnovu postojeće dokumentacije o predviđenim aktivnostima na stalnom unapređenju kvaliteta zdravstvene zaštite u Srbiji ukaže na činjenicu koliko je rad na kulturi u zdravstvenom sistemu u Srbiji zastupljen i da se ponudi odgovor na sledeća pitanja: 1) Da li je kultura i u kojem obliku uključena u planove za unapređenje zdravstvene zaštite; 2) Šta i u kojem obliku kultura u zdravstvu može da pruži i na šta sve može da utiče?

\section{KULTURA I KVALITET ZDRAVSTVENE ZAŠTITE}

Kvalitet je uključen u Zakon o zdravstvenoj zaštiti Srbije i predviđeni su određeni postupci za njegovu realizaciju. Čitavo jedno poglavlje Zakona o zdravstvenoj zaštiti bavi se kvalitetom zdravstvene zaštite, odnosno proverom kvaliteta stručnog rada i akreditacijom. Član 203. Zakona o zdravstvenoj zaštiti kaže: „Pod kvalitetom zdravstvene zaštite podrazumevaju se mere i aktivnosti kojima se, u skladu sa savremenim dostignućima medicinske, stomatološke i farmaceutske nauke i prakse, kao i savremenim dostignućima nauke i prakse, doprinosi višem nivou kvaliteta zdravstvenih usluga koje pružaju zdravstveni saradnici, povećavaju mogućnosti povoljnog ishoda i smanjuju rizik neželjenih posledica po zdravlje i zdravstveno stanje pojedinca i zajednice u celini." [7] U članu 213. se definiše značenje 
akreditacije: „Akreditacija jeste postupak ocenjivanja kvaliteta rada zdravstvene ustanove, na osnovu primene optimalnog nivoa utvrđenih standarda rada zdravstvene ustanove u određenoj oblasti zdravstvene zaštite, odnosno grani medicine." [7]

Kontinuirano unapređenje kvaliteta zdravstvene zaštite je predviđeno da bude stalni zadatak Ministarstva zdravlja, Instituta za javno zdravlje Srbije, Republičkog fonda za zdravstveno osiguranje, Instituta i zavoda za javno zdravlje i, naravno, svake pojedinačne zdravstvene ustanove [5]. Sve pomenute ustanove zajedno s Agencijom za akreditaciju rade na tome da se unapredi kvalitet zdravstvene zaštite za njene korisnike, da se razvija kultura kvaliteta i bezbednosti u zdravstvenoj zaštiti, da se razvijaju kako standardi kvaliteta, tako i pokazatelji kojima će moći da se prati kvalitet i njegovo unapređenje. Kao izuzetno važnim smatra se unapređenje zadovoljstva korisnika zdravstvenom zaštitom, ali i unapređenje zadovoljstva zaposlenih u zdravstvenim ustanovama [6].

U okviru stalnog unapređenja kvaliteta zdravstvene zaštite u Srbiji predviđene su aktivnosti kojima se razvija kultura permanentnog poboljšanja zdravstvene zaštite [4]. Te aktivnosti su vezane za:

- praćenje pokazatelja rada na nivou ustanova i svih službi u zdravstvenim ustanovama kroz definisane pokazatelja i Nacionalni akreditacioni program;

- praćenje rada komisija za kvalitet;

- praćenje kontinuiranog usavršavanja zdravstvenih radnika kao preduslova za poboljšanje kvaliteta zdravstvenih usluga;

- formulisanje novih vodiča dobre kliničke prakse;

- razvoj i implementacija kliničkih puteva;

- ispitivanje zadovoljstva korisnika radom zdravstvene službe i ispitivanje profesionalnog zadovoljstva zaposlenih $\mathrm{u}$ zdravstvenom sistemu;

- sve vrste edukacija koje su u vezi s unapređenjem kvaliteta zdravstvene zaštite.

Realizacijom predviđenih aktivnosti se očekuje:

- uspostavljanje sistema odgovornosti za kvalitet pružene zdravstvene zaštite;

- ujednačen kvalitet zdravstvenih usluga;

- smanjenje varijacija u ishodima po zdravlje pacijenata;

- unapređenje standarda kliničke prakse;

- ustanovljavanje prakse prijavljivanja neželjenih događaja;

- podržavanje primera dobre prakse i isticanje pozitivnih primera;

- efikasnije korišćenje zdravstvenih tehnologija;

- smanjenje troškova koji nastaju zbog lošeg kvaliteta radnog procesa.

Nažalost, u sklopu edukacija zdravstvenog osoblja nigde se eksplicitno ne pominju njihova kultura obraćanja korisnicima zdravstvene zaštite, važnost načina na koji se zdravstveno osoblje obraća pacijentu ili vidovi međusobnog obraćanja zdravstvenog osoblja, kao važnog segmenta kulture u zdravstvu.

\section{KULTURA U ZDRAVSTVENOM SISTEMU REPUBLIKE SRBIJE}

Rezultati istraživanja zdravlja stanovništva Srbije 2013. godine koje je Institut za javno zdravlje Srbije uradio 2014. godine pokazali su da je 53,8\% stanovnika Republike Srbije bilo zadovolj- no državnom službom, dok je privatnom službom bilo zadovoljno $64,6 \%$ ispitanika. Ova razlika i više zadovoljnih privatnom službom verovatno je posledica odnosa zaposlenih u privatnoj praksi prema korisnicima zdravstvene službe. Podizanje nivoa kulture ophođenja zdravstvenih radnika nameće se kao potreba u unapređenju zadovoljstva korisnika zdravstvenog sistema, ali i samih zdravstvenih radnika.

Institut za javno zdravlje Srbije je sačinio i Metodološko uputstvo kojim se definiše postupak izveštavanja zdravstvenih ustanova o pokazateljima kvaliteta rada, listama čekanja, kontinuiranoj edukaciji zaposlenih i zadovoljstvu pacijenata [5]. Nažalost, ni u jednom uputstvu ne piše da bilo kakav kontakt s pacijentom treba da započne besplatnim pozdravom „Dobar dan" i besplatnim osmehom.

Strategija Vlade Republike Srbije za stalno unapređenje kvaliteta zdravstvene zaštite i bezbednost pacijenata za period 2010-2015. godine predvidela je pet strateških ciljeva [7]:

1. Stvaranje uslova da korisnici (pacijenti) budu u središtu sistema zdravstvene zaštite, pri čemu su predviđena: istraživanja o zadovoljstvu korisnika pruženim zdravstvenim uslugama i analiza dobijenih podataka, praćenja rada zaštitnika prava pacijenata na nivou zdravstvene ustanove, isticanje obaveštenja za korisnike zdravstvene službe, kao i postavljanje kutija za komentare;

2. Unapređenje stručnog znanja zdravstvenih radnika i podizanje svesti o značaju stalnog unapređenja kvaliteta zdravstvene zaštite;

3. Stvaranje uslova koji promovišu kulturu stalnog unapređenja kvaliteta zdravstvene zaštite i bezbednosti pacijenata u zdravstvenim ustanovama, pri čemu je predviđeno: vođenje evidencije o neželjenim događajima, donošenje plana za unapređenje kvaliteta zdravstvene zaštite u svakoj ustanovi, praćenje i unapređenje pokazatelja kvaliteta $\mathrm{i}$ rangiranje ustanova $\mathrm{u}$ vezi s postignutim rezultatima $\mathrm{u}$ stalnom unapređenju zdravstvene zaštite;

4. Obezbeđenje sigurnosti, bezbednosti i isplativosti zdravstvenih tehnologija;

5. Obezbeđivanje finansijskih podsticaja za stalno unapređenje kvaliteta zdravstvene zaštite i bezbednosti pacijenata.

Ono što nije predviđeno ovom strategijom Vlade Republike Srbije jeste da pacijent ima pravo da učestvuje u kreiranju zdravstvene politike. Takođe, standarde i norme nije samo dovoljno doneti, nego ih treba u praksi primenjivati. Trebalo bi izbeći činjenicu da se na vratima zdravstvenih ustanova pacijenti sudaraju sa medicinskim osobljem koje potpuno nezaštićeno iznosi i unosi iz jedne u drugu zdravstvenu ustanovu epruvete s krvlju i drugi materijal za potrebe analize. Uz sve to, niko od korisnika zdravstvene zaštite ne bi trebalo da bude oslovljavan sa „čiko“, „bako“ i sl., jer se i time značajno unapređuje sam kvalitet zdravstvene zaštite [9]. Loš kvalitet zdravstvene zaštite se može lako prepoznati u stalnim skandalima izazvanim neočekivanim smrtnim slučajevima ili greškama u terapiji i lečenju. Kada se skandal pojavi, uobičajena politička reakcija je da se potraži neko koga bi trebalo okriviti za grešku. Zdravstveni radnici koji prave greške postoje i bavljenje njima jeste važno za sistem zdravstvene zaštite. Mnogo je važnije, međutim, usmeriti se na širu sliku štete koja time nastaje zbog lošeg kvaliteta, a sistemski raditi na načinima kako da se one izbegnu. Rad na stalnom unapređenju kvaliteta je jedan od mehanizama za razvoj i unapređenje sistema zdravstvene zaštite [9]. 


\section{POREĐENJE KVALITETA ZDRAVSTVENE ZAŠTITE U SRBIJI SA DRUGIM ZEMLJAMA EVROPE}

Kvalitet zdravstvene zaštite u Republici Srbiji se najbolje može oceniti poređenjem sa drugim evropskim zemljama, a naročito onim iz regiona. Evropski zdravstveni potrošački indeks je projekat kojim se zemlje u Evropi porede i rangiraju na osnovu unapred dogovorenih parametara. Svi pokazatelji koji se prikupljaju su podeljeni u nekoliko grupa. Posebnu grupu čine parametri koji se odnose na izlazne efekte prevencije i promocije [10].

Poređenje među zemljama vrši se kroz poređenje sledećih pokazatelja:

1. vakcinacija odojčadi petovalentnom vakcinom (gde se poredi procenat vakcinisane odojčadi);

2. visina krvnog pritiska (gde se poredi procenat ljudi starijih od 25 godina koji imaju pritisak veći od 140/90 mm Hg);

3. prevencija pušenja (pri čemu se na osnovu kompleksne skale upoređuju cene cigareta, zakonski regulisana zabrana pušenja, dozvoljenost pušenja u restoranima, na javnim mestima i u prevozu, potrošnja na kampanje protiv pušenja, zabrana reklamiranja duvana i pušenja, istaknutost upozorenja, tretmani koji omogućuju odvikavanje itd.);

4. prevencija alkohola (gde se koristi kompleksan pokazatelj, pri čemu se poredi konzumiranje žestokih pića kod osoba starijih od 15 godina);

5. fizička aktivnost (gde se poredi količina časova fizičkog vaspitanja tokom obaveznog školovanja);

6. vakcinacija protiv humanog papiloma virusa (gde se ocenjuje postojanje Nacionalnog programa za tinejdžerke);

7. smrtnost u saobraćaju (ovo je nov pokazatelj, jer se broj poginulih u saobraćaju veoma brzo povećava u svim zemljama).

Republika Srbija ima prostora za poboljšanje izlaznih efekata promotivnih i preventivnih aktivnosti kroz povećanje procenta vakcinisane odojčadi, za veći rad na prevenciji pušenja i konzumiranja alkohola, a naročito u realizaciji Nacionalnog programa za tinejdžerke. S druge strane, u pozitivnom smeru su izražene aktivnosti na smanjenju visine krvnog pritiska kod stanovništva i značajno su efikasnije u odnosu na zemlje u okruženju (Tabela 1).
Ponašanje zdravstvenog osoblja iz ugla korisnika zdravstvene zaštite nije ocenjivano, ali je zato posebno poglavlje posvećeno ocenjivanju prava pacijenata i njihove informisanosti (Tabela 2).

Poređenje među zemljama se vrši kroz osnovne pokazatelje:

1. zdravstveni zakon zasnovan na pravima pacijenata;

2. organizacije pacijenata uključene u zdravstvenu politiku;

3. osiguranje od greške u lečenju;

4. pravo pacijenta na mišljenje drugog lekara;

5. pristup sopstvenom zdravstvenom kartonu;

6. registar savesnih lekara;

7. interaktivni 24-časovni telefon za zdravstvenu pomoć sedam dana u nedelji;

8. katalog pružalaca usluga s ocenama.

Od bivših jugoslovenskih republika, samo je Makedonija postigla odlične rezultate u većini pokazatelja. Srbiji je potrebno da unapredi uključenost pacijenata u zdravstvenu politiku kroz podizanje njihove informisanosti, te da oformi registar savesnih lekara i katalog rangiranih pružalaca zdravstvenih usluga, da bi bila ocenjena odličnom ocenom (Tabela 2).

\section{ZAKLJUČAK}

Kultura u zdravstvu, kako ona u nadležnosti korisnika, tako i kod pružalaca zdravstvenih usluga, jedan je od ključnih faktora unapređivanja zdravstvenog sistema u Srbiji. Analizom postojeće dokumentacije o predviđenim aktivnostima na stalnom unapređenju kvaliteta zdravstvene zaštite u Srbiji utvrđeno je da je na ovom polju napravljen jasan iskorak strateškim planom Vlade Republike Srbije iz 2010. godine, ali da postoji još prostora za dalji napredak. Ovde se prevashodno misli na uključivanje korisnika u kreiranje zdravstvene politike, ali i primenjivanje već donetih standarda i normi u svakodnevnom radu pružalaca zdravstvenih usluga, kako bi se osiguralo da zakonska regulativa ne funkcioniše samo „na papiru“. Takođe, ne sme se zaboraviti ni na edukaciju korisnika zdravstvene zaštite, da bi se podigao opšti nivo svesti o važnosti zdravstvene kulture onih zbog kojih zdravstveni sistem i postoji. 